\title{
Development of a Method by HPLC to Determine LAS and its Application in Anaerobic Reactors
}

\author{
Iolanda C. S. Duarte, * Lorena L. Oliveira, Andréa P. Buzzini, M. Angela T. Adorno and \\ M. Bernadete A. Varesche \\ Departamento de Hidráulica e Saneamento, Escola de Engenharia de São Carlos, Universidade de São Paulo, \\ Av. Trabalhador Sãocarlense, 400, 13566-590 São Carlos-SP, Brazil
}

\begin{abstract}
Este trabalho descreve o desenvolvimento e a validação de um método que usa cromatografia líquida de alta eficiência para determinação de Alquilbenzeno Linear Sulfonado (LAS) em amostras de águas provenientes de reatores anaeróbios. O padrão de LAS aplicado foi ácido dodecilbenzeno sulfônico-sal sódico, que apresentou 4 picos principais no cromatograma, relacionados aos diferentes homólogos da cadeia alquílica linear. Diferentes condições cromatográficas foram testadas, tais como, fases estacionárias C-18, C-12 e C-8; detectores de ultravioleta e de fluorescência, composição da fase móvel e tempo de programação do gradiente de eluição. A melhor condição cromatográfica obtida foi com a coluna C-8, fase móvel: metanol/ perclorato de sódio $0,075 \mathrm{~mol} \mathrm{~L}^{-1}$ e detector de fluorescência. A validação deste método foi feita através das curvas de calibração de LAS, usando água e substrato sintético como solventes. O método foi validado com o objetivo de demonstrar sua precisão, linearidade, limite de detecção para cada homólogo e a sua precisão instrumental.
\end{abstract}

This work describes the development and validation of a method using High Performance Liquid Chromatography (HPLC) for Linear Alkylbenzene Sulfonate (LAS) determination in sample of wastewater from anaerobic reactors. The applied LAS standard was the dodecylbenzene sulfonic acid-sodium salt, which presents four main peaks in the chromatogram, related to different homologous of the linear alkyl chain. Different chromatographic conditions were tested with C-18, C-12 and C-8 as stationary phases, ultraviolet and fluorescence detectors, mobile phase (MP) compositions and programming time of elution gradient. The best chromatographic condition was obtained with the C-8 column, MP: methanol and of sodium perchlorate $\left(0.075 \mathrm{~mol} \mathrm{~L}^{-1}\right)$. The validation of this method was made with the calibration of LAS curves using water and synthetic substrate as solvents. The method was validated in order to demonstrate its precision, linearity, limit of detection of each homolog and its instrumental precision.

Keywords: Linear Alkylbenzene Sulfonate, High Performance Liquid Chromatography, validation

\section{Introduction}

Linear Alkylbenzene Sulfonate (LAS) is an anionic surfactant that was introduced in the world market in 1964. LAS contains a sulfonated aromatic ring attached to a linear alkyl chain at the para position. ${ }^{1}$ The commercial product is a mixture of homologues containing 10 to 13 carbon atoms in the alkyl chain. ${ }^{2}$ Each one of these homologues consists of positional isomers resulting from the attachment of the phenyl ring to the carbon atoms of the linear alkyl chain. ${ }^{3,4}$

*e-mail: iolanda.duarte@gmail.com
LAS is present in most of the detergent formulations for domestic and industrial uses and it is also responsible for the formation of foam in rivers, causing the reduction of the available oxygen for aquatic organisms. A wide variety of methods have been used to determine LAS concentration in commercial products and environmental samples. The Methylene Blue Active Substance (MBAS) has been widely used as a standard method for measuring sulfonate and sulfate-based anionics in wastewater. ${ }^{5}$

This method (MBAS) takes a long time to be prepared and is sensitive with a detection limit of $10 \mu \mathrm{g}$. It can suffer interferences due to the presence of other 
substances, such as: organic sulfonates, sulfates, carboxylates, phenols and inorganic thiocyanates, cyanates, nitrates and chlorides. These substances may increase or decrease the methylene blue concentration into the chloroform phase. The lower or higher methylene blue concentration can be resultant of the competition between some substances such as cationic surfactants, other cationic materials and anionic surfactants in the formation of ionic pairs. ${ }^{6}$ The method requires a significant volume of sample $(100 \mathrm{~mL})$ and uses chloroform and sulfuric acid. ${ }^{2}$

The Infrared spectroscopy combined with LAS extraction applied to the sea sediment is specific for LAS detection, but is not sensitive and not specific for the detection of its homologues. ${ }^{7}$

The Atomic Absorption Spectrometry based on metalLAS complex solvent extraction from seawater ${ }^{8,9}$ is also not specific for LAS. ${ }^{7}$

The determination of the alkyl chain distribution of LAS has been carried out by gas chromatography. This method, however, requires the conversion of LAS into volatile derivatives before the analysis. ${ }^{10}$ The gas chromatograph (GC), coupled with the mass spectrophotometer (MS), ${ }^{11}$ combined with LAS solvent extraction is sensitive and involves many steps, consuming time to prepare the samples due to the conversion of LAS to volatile derivatives. The anionic surfactants have low volatility and GC procedures require the conversion of the surfactants into volatile hydrocarbons by desulfonation ${ }^{12}$ or conversion into volatile compounds, such as sulfophenyl chlorides, sulfophenyl fluorides or methyl esters. ${ }^{13}$

HPLC is widely accepted as a specific method for the determination of LAS in various environmental samples. ${ }^{14}$ LAS concentration in river waters was determined without any pre-concentration and pre-purification. ${ }^{15}$ This method, however, can be applied only to relatively clean aqueous samples that have quite high contents of LAS. ${ }^{16}$ The Reversed-phase HPLC must be considered the routine method for LAS analysis. ${ }^{17}$

Liquid chromatography procedures for separation and determination of LAS surfactants usually employ C-8 or C-18 columns and mobile phases containing organic substances and water. This mobile phase commonly contains an electrolyte, ${ }^{18-20}$ anion exchangers, ${ }^{21}$ or reversed stationary phases in combination with mobile phases containing ionic interaction reagents such as quaternary ammonium salts. ${ }^{16}$

The reversed-phase HPLC method provides the separation of LAS mixture and may use various chromatographic detectors, as spectrometry ultraviolet (UV), ${ }^{22}$ fluorescence ${ }^{4,23,24}$ and mass spectrometry (MS). ${ }^{25,26}$
Most HPLC methods with UV detector require the mobile phase to contain either sodium perchlorate ${ }^{25}$ or additive, such as triethylamine and acetic acid. ${ }^{26,27}$

The practical application of mobile phases containing high amounts of those compounds, particularly sodium perchlorate $\left(10 \mathrm{~g} \mathrm{~L}^{-1}\right)$, can abbreviate the useful life of the column. The higher the content of sodium perchlorate present in the mobile phase, the higher is the retention of LAS in the column. ${ }^{10}$

The purpose of this work was to develop and validate a method, by HLPC, for LAS analysis from samples of Horizontal Anaerobic Immobilized Biomass (HAIB) reactor.

\section{Experimental}

\section{Development of the chromatographic method}

Three columns were tested on the development of the chromatographic method to quantify LAS by HPLC. A Shimadzu liquid chromatography system equipped with LC-10AD $\mathrm{VP}_{\mathrm{VP}}$ pump, FCV-10AL $\mathrm{V}_{\mathrm{VP}}$ valve, fluorescence (RF$10 \mathrm{~A}_{\mathrm{XL}}$ ) and UV (SPD-M10 $\mathrm{A}_{\mathrm{vP}}$ ) detectors and controller SCL-10A $\mathrm{A}_{\mathrm{vP}}$ was used.

Firstly, it was tested the C-18 column with an isocratic elution, applying a mixture of methanol and water (80/

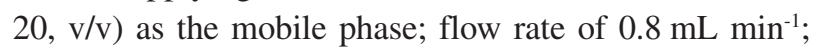
column temperature of $37{ }^{\circ} \mathrm{C}$ and the UV detector at $\lambda=230 \mathrm{~nm}$.

The second tested column was a Synergi C-12 with a gradient elution and a mixture of acetonitrile and water $(70 / 30, v / v)$ and $0.15 \mathrm{~mol} \mathrm{~L}^{-1}$ of sodium perchlorate in water as mobile phase; flow rate of $1.0 \mathrm{~mL} \mathrm{~min}^{-1}$ and the UV detector at $\lambda=197 \mathrm{~nm}$ and fluorescence detector at $\lambda_{\text {excitation }} 225 \mathrm{~nm}$ and $\lambda_{\text {emission }} 290 \mathrm{~nm}$.

The last tested column was a C-8 column with an isocratic elution, using a mixture of methanol and $0.15 \mathrm{~mol}$ $\mathrm{L}^{-1}$ of sodium perchlorate in water $(80 / 20, \mathrm{v} / \mathrm{v})$ as mobile phase; different flow rates of $1.5,0.8$ and $0.5 \mathrm{~mL} \mathrm{~min}^{-1}$; column temperature of $32{ }^{\circ} \mathrm{C}$; UV $(\lambda=230 \mathrm{~nm})$ and fluorescence $\left(\lambda_{\text {exc }}=225 \mathrm{~nm} ; \lambda_{\text {em }}=290 \mathrm{~nm}\right)$ detectors.

Different time programming of gradient elution, with methanol and $0.075 \mathrm{~mol} \mathrm{~L}^{-1}$ of sodium perchlorate in water as mobile phase and column temperature of $35^{\circ} \mathrm{C}$, were tested with the fluorescence detector. One of the programming times of the tested elution gradient is described in Table 1.

\section{HLPC conditions}

The HPLC methodology is based on reversed phase 
Table 1. Time programming of the gradient elution tested to determine LAS by HPLC

\begin{tabular}{lcc}
\hline time / $\min$ & \% Solvent A & \% Solvent B \\
\hline 20 & 95 & 5 \\
25 & 80 & 20 \\
28 & 80 & 20 \\
32 & STOP & STOP \\
\hline
\end{tabular}

Solvent A: Methanol; Solvent B: $\mathrm{NaClO}_{4} 0.075 \mathrm{~mol} \mathrm{~L}^{-1}$ (aqueous solution).

separation with methanol/water as mobile phase, containing sodium perchlorate as a phase modifier.

The best HPLC detection of LAS was achieved in the C-8 column at a temperature of $35^{\circ} \mathrm{C}$.

The initial mobile phase consisted of $90 \%$ of solvent A (methanol) and $10 \%$ of solvent B $\left(0.075 \mathrm{~mol} \mathrm{~L}^{-1}\right.$ of $\mathrm{NaClO}_{4}$ in water). The concentration of solvent $\mathrm{A}$ decreased to $20 \%$ in 25 minutes using the elution gradient.

The time programming of gradient used in the determination of LAS is described in Table 2 and was chosen because results in a better separation of the homologues of LAS that are present in the standards and samples, with better chromatographic efficiency.

Table 2. Time programming of the gradient elution chosen to determine LAS by HPLC

\begin{tabular}{lcc}
\hline time $/ \min$ & \% Solvent A & \% Solvent B \\
\hline 25 & 90 & 10 \\
35 & 70 & 30 \\
38 & 70 & 30 \\
48 & STOP & STOP \\
\hline
\end{tabular}

Solvent A: Methanol; Solvent B: $\mathrm{NaClO}_{4} 0.075 \mathrm{~mol} \mathrm{~L}^{-1}$ (aqueous solution).

The flow rate was maintained at $0.5 \mathrm{~mL} \mathrm{~min}{ }^{-1}$ and the column effluent was monitored by fluorescence detection with $\lambda_{\text {excitation }}=225 \mathrm{~nm}$ and $\lambda_{\text {emission }}=290 \mathrm{~nm}$.

It was necessary to rinse extensively the column with a mixture of water/ methanol $(40 / 60, v / v)$ at the end of each week in order to prevent the obstruction of the column by the crystallization, inside the column, of the inorganic salt (sodium perchlorate) that was present in the mobile phase.

\section{Preparation of the standards}

The dodecylbenzene sulfonic acid-sodium salt (Sigma), with $80 \%$ of purity, was used as the standard solution of LAS.

The data of the calibration curves were obtained by the dilution of LAS standard solution with three replications each. The dilution was made in ultra purified water and in a synthetic substrate simulating sanitary sewage. This synthetic substrate contained $420 \mathrm{mg} \mathrm{L}^{-1}$ of meat extract, $115 \mathrm{mg} \mathrm{L}^{-1}$ of starch, $80 \mathrm{mg} \mathrm{L}^{-1}$ of sucrose, $320 \mathrm{mg} \mathrm{L}^{-1}$ of sodium bicarbonate and $5 \mathrm{~mL} \mathrm{~L}^{-1}$ of mineral solution ${ }^{28}$ was used as solvent to obtain the LAS concentrations of $0.8 ; 1.6 ; 4.0 ; 8.0 ; 11.0 ; 14.0$; and 16.0 $\mathrm{mg} \mathrm{L} \mathrm{L}^{-1}$, respectively.

\section{Validation of the parameters}

Linearity. The linearity of the detector response for the prepared dilutions was assessed by the linear regression method, regarding the values of each area related to the corresponding 1,2, 3 and 4 peaks on the chromatogram (measured in $\mathrm{mg} \mathrm{L}^{-1}$ ).

Precision. The precision of the system was expressed as the coefficient of variation $(\mathrm{CV} \%)$ of the retention times for each homologue present in the standard, at different concentrations.

Instrumental precision. The instrumental precision of the assay (as coefficient of variation, $\mathrm{CV} \%$ ) was estimated by the retention time of nine repeated injections of the standard solution with $14 \mathrm{mg} \mathrm{L}^{-1}$ of LAS in water.

Limit of detection. The limit of detection (LOD) for each peak of the calibration curves was calculated according to the following expression:

$L O D=\left(3 S E_{b}+b\right) / m$

where $\mathrm{SE}_{\mathrm{b}}$ is the standard error of the intercept, ${ }^{29} \mathrm{~b}$ is the linear coefficient and $\mathrm{m}$ is the angular coefficient.

Limit of Quantification (LOQ). The limit of quantification represents the least concentration of a compound that can be measured, by determined experimental procedure,$^{30}$ and was calculated according to the following expression:

$\mathrm{LOQ}=10 \times \mathrm{SD} / \mathrm{m}$

where SD is the standard deviation and $\mathrm{m}$ is the angular coefficient.

Recovery. The recovery of LAS in aqueous samples was measured by adding known LAS concentration to the synthetic substrate. The results were calculated using the following expression: 
$\%$ recovery $=\left(\mathrm{mg} \mathrm{L}^{-1}\right.$ obtained $/ \mathrm{mg} \mathrm{L}^{-1}$ theoretical $) \times 100$

where $\mathrm{mg} \mathrm{L}^{-1}$ obtained = concentration of LAS used in the calibration curve with water; $\mathrm{mg} \mathrm{L}^{-1}$ theoretical = concentration of LAS considered for each peak.

\section{Applicability of the method}

Various kinds of samples were analyzed, including influent, effluent and LAS adsorbed in biofilm, from an Horizontal Anaerobic Immobilized Biomass (HAIB) reactor.

LAS concentration in the HAIB reactor was monitored during 313 days of operation, treating synthetic substrate simulating sanitary sewage, with Hydraulic Detention Time (HDT) of 12 hours at $30{ }^{\circ} \mathrm{C}$. The added concentrations of LAS in the influent at the beginning of operation and later were of 7 and $14 \mathrm{mg} \mathrm{L}^{-1}$, respectively.

A bench-scale HAIB reactor was built of bore-silicate glass with $100 \mathrm{~cm}$ of length (L), $5 \mathrm{~cm}$ of diameter (D) and $2000 \mathrm{~mL}$ of total volume. Five sampling ports were built along its length (L), with L/D of 1, 5, 10, 15 and 19, and three gas collectors. The reactor was kept in a chamber with controlled temperature $\left(30 \pm 2{ }^{\circ} \mathrm{C}\right)$ and fed by a peristaltic pump.

The inoculum used in the HAIB reactor was sludge from an Up-flow Anaerobic Sludge Blanket (UASB) reactor treating sanitary sewage in the University of São Paulo, São Carlos city (Brazil). This sludge was immobilized in $25 \mathrm{~g}$ of polyurethane foam cubes with $5 \mathrm{~mm}$ and apparent density of $23 \mathrm{~kg} \mathrm{~m}^{-3}$. The bed porosity was calculated at $40 \%$ resulting in a useful volume of $800 \mathrm{~mL} .{ }^{31}$

\section{Results and Discussion}

\section{Effect of the column and the mobile phase on the LAS} separation

The chromatograms obtained with the C-12 and C-18 columns presented peaks with low resolution, even after changing the composition of the mobile phase, the column temperature and the detectors (Figure 1), however, the use of C-8 column showed peaks with higher resolution (Figure 2).

The best chromatographic condition was chosen by the best resolution of the peaks, once the standard solution contained various homologues and isomers that appeared like four distinct peaks. The mobile phase used to obtain this chromatographic separation was methanol (solution A) and $0.075 \mathrm{~mol} \mathrm{~L}^{-1}$ of an aqueous solution of sodium perchlorate (solution B) with a gradient elution (Table 2, Figure 3).

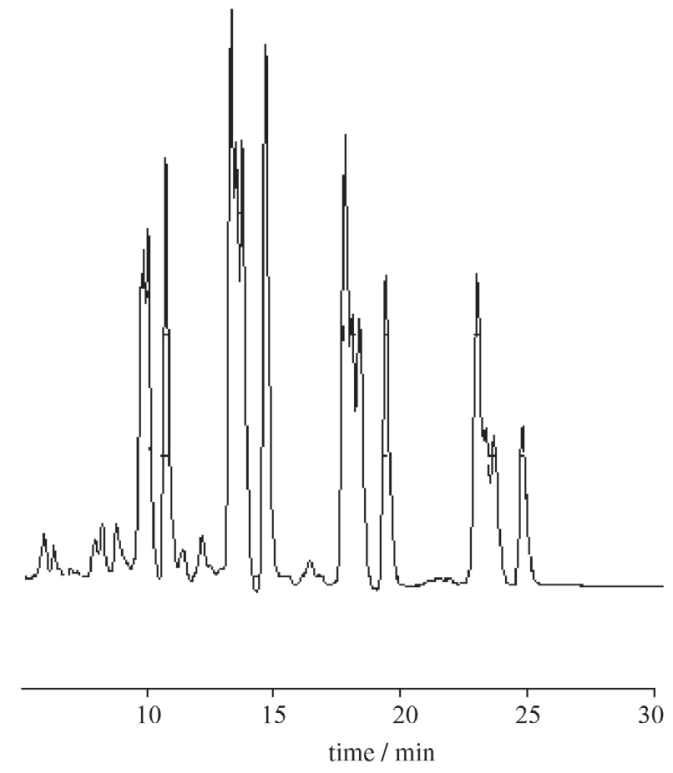

Figure 1. Chromatogram of linear alkylbenzene sulfonate (LAS). Conditions: column C12, gradient elution, MP: aqueous solution of $\mathrm{NaClO}_{4}$ $0.15 \mathrm{~mol} \mathrm{~L}^{-1}$ (Solution A) and acetonitrile:water (70:30) (solution B); flow rate: $1.0 \mathrm{~mL} \mathrm{~min}{ }^{-1}$, column temperature $30^{\circ} \mathrm{C}$, detector fluorescence $\lambda_{\text {excitation }} 225 \mathrm{~nm}$ and $\lambda_{\text {emission }} 290 \mathrm{~nm}$.

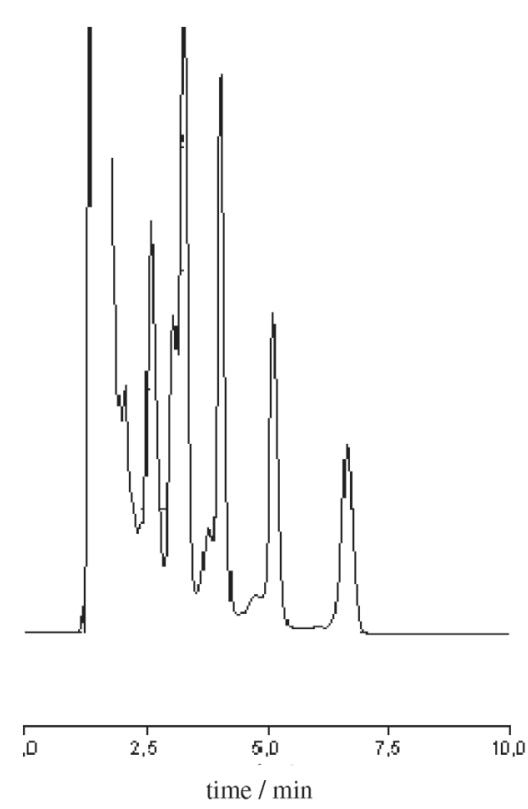

Figure 2. Typical chromatogram of linear alkylbenzene sulfonate (LAS). Conditions: column C-8, isocratic elution, MP: methanol:water (80:20) with $\mathrm{Na}_{2} \mathrm{ClO}_{4} 0.15 \mathrm{~mol} \mathrm{~L}^{-1}$; flow rate: $1.5 \mathrm{~mL} \mathrm{~min}^{-1}$, column temperature $35^{\circ} \mathrm{C}$, detector fluorescence $\lambda_{\text {excitation }} 225 \mathrm{~nm}$ and $\lambda_{\text {emission }} 290 \mathrm{~nm}$.

The LAS anions are retained on the stationary phase surface by the interaction between the alkyl chain of the anionic surfactant and the stationary phase. The retention of LAS surfactants increases in reversed stationary phases according to the ionic strength of the mobile phase and the ionic strength of electrolytic cation. The optimum cations 


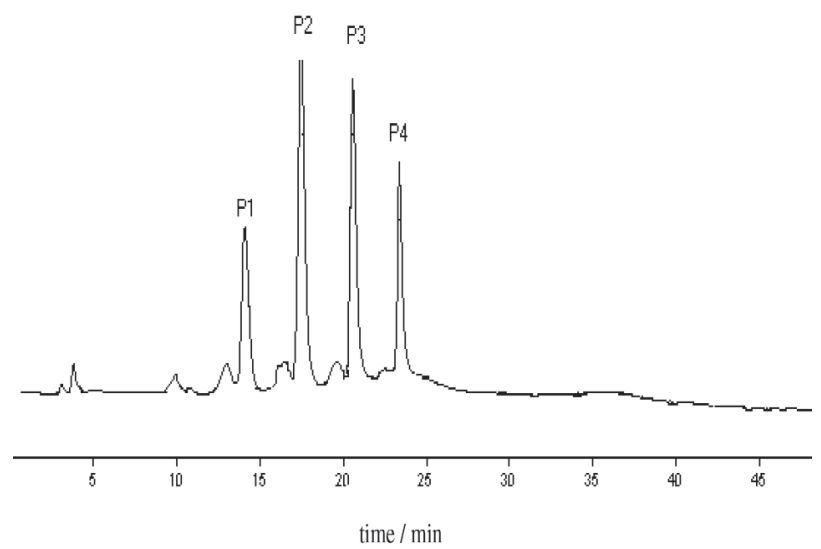

Figure 3. Typical chromatogram of a solution of linear alkylbenzene sulfonate (LAS). At $14 \mathrm{mg} \mathrm{L}^{-1}$. Conditions: column C-8, gradient elution, MP: aqueous solution of $\mathrm{NaClO}_{4} 0.075 \mathrm{~mol} \mathrm{~L}^{-1} /$ methanol; flow rate: 0.5

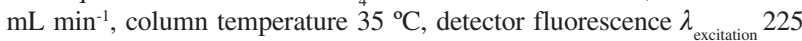
$\mathrm{nm}$ and $\lambda_{\text {emission }} 290 \mathrm{~nm}$. P1, P2, P3 and P4: are the homologues and isomers peaks of LAS.

of the mobile phase are $\mathrm{Na}^{+}, \mathrm{Mg}^{2+}$ and $\mathrm{Ba}^{2+}$, however $\mathrm{Na}^{+}$ is the most appropriated to the usage. ${ }^{32}$ LAS was eluted at the solvent front in the absence of sodium perchlorate in the mobile phase $\left(\mathrm{CH}_{3} \mathrm{CN} / \mathrm{H}_{2} \mathrm{O}, 45 / 55\right.$, v/v) ${ }^{10}$ Similar separation of LAS will be obtained if an aqueous acetonitrile solution containing other inorganic salts such as sodium chloride, sodium nitrate and ammonium chloride are used as mobile phases instead of sodium perchlorate. The addition of a phase modifying agent, such as sodium perchlorate, to the mobile phase is necessary to obtain sufficient retention of the alkylbenzene sulfonates in the analytical column. The use of a gradient system results in a better separation of the individual LAS homologues. ${ }^{33}$

Excellent separations of the peaks of homologues of LAS were obtained from the usage of the C-8 column as the stationary phase and the LAS homologues were separated with high resolution, with retention times of 14, 17, 20 and 23 minutes for peaks 1, 2, 3 and 4, respectively and all the isomers of each LAS homologue co-elutes into a single peak, ${ }^{16}$ facilitating the interpretation of the chromatogram. These obtained results were the opposite of those obtained with the C-18 column, ${ }^{15,33-35}$ where the LAS homologues cannot be separated as different peaks.

\section{Determination of LAS}

To obtain all the components of LAS, without compromising the analysis time and the method sensitivity, some gradient elution techniques in liquid chromatography (LC) were used to diminish gradually and control the power of the column on the chromatographic run. ${ }^{35}$
It was possible to correlate the area of each peak with the known concentration of each standard in order to establish the exact concentration of each one of the four main peaks present in the chromatogram and perform individually the calibration of the curves (Table 3).

Table 3. Standard solutions (in water) of LAS used to the calibration curve and their concentrations in $\mathrm{mg} \mathrm{L}^{-1}$ by HPLC

\begin{tabular}{lcccc}
\hline LAS/ $\left(\mathrm{mg} \mathrm{L}^{-1}\right)$ & Peak 1 & Peak 2 & Peak 3 & Peak 4 \\
\hline 0.8 & 0.10 & 0.24 & 0.24 & 0.23 \\
1.6 & 0.24 & 0.49 & 0.44 & 0.36 \\
4.0 & 0.70 & 1.40 & 1.12 & 0.78 \\
8.0 & 1.40 & 2.83 & 2.25 & 1.56 \\
11.2 & 1.97 & 3.98 & 3.14 & 2.11 \\
14.0 & 2.46 & 4.91 & 3.95 & 2.67 \\
16.0 & 2.89 & 5.75 & 4.47 & 2.90 \\
\hline
\end{tabular}

The percentage distribution of the LAS peaks in the standard solutions was equal to $18 \%$ for peak $1 ; 36 \%$ for peak 2; $28 \%$ for peak 3 and $18 \%$ for peak 4 . The main peaks obtained on the chromatogram corresponded to homologues of LAS that were present in the used standard and must be identified as soon as possible by GC/MS.

\section{Linearity, instrumental precision, precision, limit of} detection and limit of quantification

The HPLC method was validated by the determination of its linearity, instrumental precision, precision, Limit of Detection (LOD) and Limit of Quantification (LOQ). The method precision was evaluated according to the retention time. The precision of the system, expressed as the CV\%, was better than $1.0 \%$ for the standards in water and $4.0 \%$ for the standards in synthetic substrate.

Tables 4 and 5 summarize the regression data for the calibration curves and the individual LOD and LOQ calculations of the peaks. The LOD and LOQ based on the calibration curves are more realistic because of the method precision. ${ }^{36}$

The LOD and LOQ values were smaller for the standard solutions in water than those obtained in synthetic substrate as solvent. The homologue represented by peak 2 presented a smaller LOD and LOQ than those observed on the other peaks. On the other hand, it is not important for the analysis, once the concentration of peak 2 is two times greater than the concentration of peak 1 in the considered standard. For this reason, peak 2 was considered as linear dodecylbenzenesulfonate. Peak 1 had the lowest detection and quantification limits $(0.37 \mathrm{mg}$ $\mathrm{L}^{-1}$ and $1.23 \mathrm{mg} \mathrm{L}^{-1}$, respectively) for the standard solutions in synthetic substrate and peak 2 had the highest detection 
Table 4. Regression curves, linearity, limit of detection (LOD) and limit of quantification of each homologue of LAS in water by HPLC

\begin{tabular}{lccccc}
\hline Peaks & Regression equation & $\mathrm{R}^{2}$ & Concentration range / $\left(\mathrm{mg} \mathrm{L}^{-1}\right)$ & LOD / (mg L-1) & LOQ / $\left.(\mathrm{mg} \mathrm{L})^{-1}\right)$ \\
\hline 1 & $\mathrm{y}=128790 \mathrm{x}+18492$ & 0.9848 & $0.09-2.89$ & 0.43 & 1.43 \\
2 & $\mathrm{y}=137009 \mathrm{x}+1862.4$ & 0.9976 & $0.23-5.74$ & 0.01 & 0.03 \\
3 & $\mathrm{y}=136430 \mathrm{x}+2988.3$ & 0.9969 & $0.23-4.46$ & 0.02 & 0.07 \\
4 & $\mathrm{y}=135326 \mathrm{x}+4774.7$ & 0.9966 & $0.23-2.89$ & 0.03 & 0.10 \\
\hline
\end{tabular}

Table 5. Regression curves, linearity, limit of detection (LOD), limit of quantification of each homologue of LAS in synthetic substrate by HPLC

\begin{tabular}{lccccc}
\hline Peaks & Regression equation & $\mathrm{R}^{2}$ & Concentration range / $\left(\mathrm{mg} \mathrm{L}^{-1}\right)$ & LOD / (mg L-1) & LOQ / (mg L-1) \\
\hline 1 & $\mathrm{y}=124124 \mathrm{x}+5290.4$ & 0.9834 & $0.13-3.05$ & 0.37 & 0.69 \\
2 & $\mathrm{y}=124814 \mathrm{x}+9251.5$ & 0.9837 & $0.24-5.94$ & 0.54 & 2.30 \\
3 & $\mathrm{y}=123521 \mathrm{x}+12134$ & 0.9840 & $0.21-4.34$ & 0.42 & 1.80 \\
4 & $\mathrm{y}=121164 \mathrm{x}+12875$ & 0.9800 & $0.23-2.5$ & 1.40 \\
\hline
\end{tabular}

and quantification limits $\left(0.69 \mathrm{mg} \mathrm{\textrm {L } ^ { - 1 }}\right.$ and $2.30 \mathrm{mg} \mathrm{L}^{-1}$, respectively).

The resulting calibration curves were linear in the investigated range, both with water and synthetic substrate as solvents for the standard solutions.

The correlation coefficients obtained were greater than or equal to 0.98 for all the calibration curves. The precision of the method was measured by analyses in triplicate repetition (Table 6) with coefficients of variation lower or equal to $3.17 \%$. The standards in water and in synthetic substrate were measured by repeated analyses (triplicates of $0.8 ; 1.6 ; 4.0 ; 8.0 ; 11.0 ; 14.0$ and $16.0 \mathrm{mg} \mathrm{L}^{-1}$ ).

Table 6. Precision of the method for retention time ( $\mathrm{n}=3$ for the peaks) for each homologue of LAS by HPLC

\begin{tabular}{lcccc}
\hline Peaks & $\mathrm{t}_{\mathrm{r}(\mathrm{w})} / \min$ & $\mathrm{CV}_{\mathrm{w}} / \%$ & $\mathrm{t}_{\mathrm{r}(\mathrm{s})} / \mathrm{min}$ & $\mathrm{CV}_{(\mathrm{s})} / \%$ \\
\hline 1 & $14.15 \pm 0.09$ & 0.66 & $14.14 \pm 0.21$ & 1.52 \\
2 & $17.51 \pm 0.08$ & 0.46 & $17.51 \pm 0.19$ & 1.09 \\
3 & $20.61 \pm 0.07$ & 0.38 & $20.61 \pm 0.19$ & 0.95 \\
4 & $23.40 \pm 0.06$ & 0.28 & $23.55 \pm 0.74$ & 3.17 \\
\hline \multicolumn{4}{l}{$\mathrm{W}$ = standards in water; $\mathrm{S}=$ standards in synthetic substrate. }
\end{tabular}

The instrumental precision of the assay, estimated by the coefficient of variation (CV\%) for the retention times was calculated from nine injections of the same standard solution $\left(14 \mathrm{mg} \mathrm{L}^{-1}\right)$ and resulted in a variable range from 0.7 to $1.4 \%$ for each peak (Table 7).

It can be observed that the best detection limit was obtained for the calibration curve using water when compared to the ones with synthetic substrate as solvent for the standard solutions.

The results reported in Table 7 relate to the mean recovery values for the four individual peaks present in the used standard of LAS. The recovery percentages of this method for peaks 1, 2, 3 and $4(n=9)$ were $98 \%, 101 \%$, $100 \%$ and $99 \%$, respectively.
Table 7. Instrumental precision of the retention times obtained from 14 $\mathrm{mg}$ LAS/L in synthetic substrate $(\mathrm{n}=9)$ and recovery of homologues of commercial LAS by HPLC

\begin{tabular}{lcccc}
\hline Peaks & Mean \pm SD & CV $/ \%$ & Recovery & Standard deviation \\
\hline 1 & $14.1 \pm 0.2$ & 1.46 & $98 \%$ & 15 \\
2 & $17.4 \pm 0.2$ & 1.09 & $101 \%$ & 23 \\
3 & $20.5 \pm 0.18$ & 0.87 & $100 \%$ & 20 \\
4 & $23.3 \pm 0.17$ & 0.74 & $99 \%$ & 27 \\
\hline
\end{tabular}

\section{Applications}

The proposed HPLC method was applied to determine the concentration of LAS in the influent and the effluent of a HAIB.

Despite of its lower precision in samples, which contain other substances moreover than LAS, the method was good enough to control the effluent of HAIB reactor used in the treatment of synthetic substrate containing LAS. This can be observed with the results obtained with the standards with synthetic substrate as solvent (Table 7). It was possible to estimate the adsorbent potential of the support material, used to immobilize the biomass in the reactors. About $1400 \mathrm{mg}$ of LAS mass was applied in the 108 first days during the reactor operation and $800 \mathrm{mg}$ was obtained in the effluent.

The mass balance in the system indicated LAS removal of $41 \%$ until the $108^{\text {th }}$ day of operation, when the concentration of LAS in the influent and effluent were similar (Figure 4).

Such removal was attributed to the activity of the adsorption phenomena in the polyurethane foam and biofilm, in addition with the biological removal. After this period, it was considered that the reactor achieved the saturation potential of LAS. Thus, all the removal of LAS can be considered as biological degradation. 


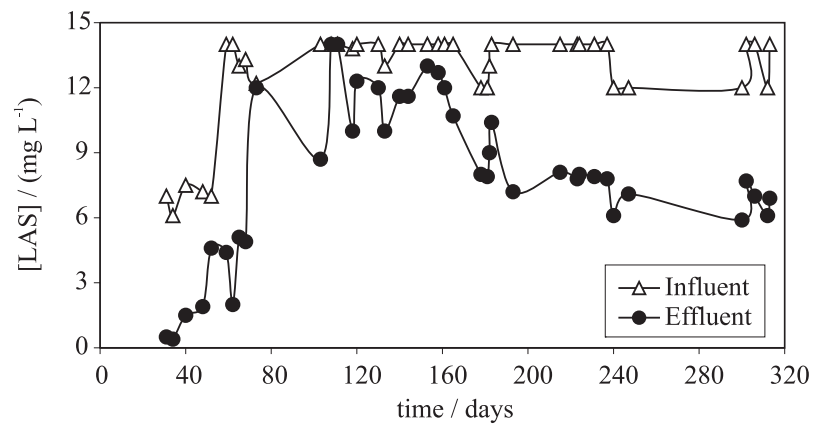

Figure 4. Temporal variation of LAS obtained in influent and effluent in the HAIB reactor.

The reactor reached $37 \%$ of degradation with the application of $4400 \mathrm{mg}$ of LAS from the $109^{\text {th }}$ day until the end of the operation ( $313^{\text {th }}$ day), presenting $2800 \mathrm{mg}$ of residual concentration in the effluent. It was possible to carry out the global mass balance of the system after the extraction of the adsorbed LAS from the polyurethane foam. The total mass of LAS applied to the reactor was $5800 \mathrm{mg}$, with $3600 \mathrm{mg}$ in the effluent and $165 \mathrm{mg}$ adsorbed in the foam with biofilm, indicating $35 \%$ of biological degradation.

\section{Conclusions}

The best chromatographic condition was obtained with the C-8 column $(15 \mathrm{~cm} \times 4.6 \mathrm{~mm}, 5 \mu \mathrm{m})$, MP: methanol and aqueous solution of sodium perchlorate $(0.075 \mathrm{~mol}$ $\mathrm{L}^{-1}$ ). The validation of this method was made with the calibration of LAS curves using water and synthetic substrate as solvents.

The accurate HPLC approach used in this work to quantify LAS was validated assessing the linearity, precision, instrumental precision, limit of detection, limit of quantification and recovery. This method presented a chromatogram with four well-resolved peaks of the four main homologues of LAS present in the commercial surfactant that can be quantified.

The analyzed samples by this method do not need any previous preparation. Thus, this method resumes in a simple and rapid method if compared to other methods such as MBAS that are used in the quantification of anionic surfactants.

This method was satisfactorily applied to effluents of wastewater treatment. This fact makes it available for the quality control of surface waters and samples from bioreactors treating sanitary sewage.

The presented analytical procedure employing reversed-phase HPLC is particularly useful for routine analyses of a large number of samples due to its detection selectivity, simplicity and short analysis time. Moreover, the use of low concentrations of salt in the mobile phase also increases the useful life of the column.

\section{Acknowledgments}

The authors are grateful to Fundação de Amparo à Pesquisa do Estado de São Paulo (FAPESP), Conselho Nacional de Desenvolvimento Científico e Tecnológico (CNPq).

\section{References}

1. Manousaki, E.; Psillakis, E.; Kalogerakis, N.; Mantzavinos, D.; Water Res. 2004, 38, 3751.

2. Wangkarn, S.; Soisungnoen, P.; Rayanakorn, M.; Grudpan, K.; Talanta 2005, 67, 686.

3. Vogt, C.; Heining, K.; Fresenius, J.; Anal. Chem. 1999, 363, 612.

4. León, V. M.; González-Mazo, A.; Gómez-Parra, J.; J. Chromatogr., A 2000, 899, 211.

5. Greenberg, A. E.; Clesceri, L. S.; Eaton, A. D.; Standard Methods for the Examination of Water and Wastewater. $18^{\text {th }}$ ed., American Public Health Association: Washington, DC, 1992, Section 5540C, pp. 5-36.

6. Levine, L. H.; Judkins, J. E.; Garland, J. L.; J. Chromatogr., A 2000, 874, 207.

7. Kikuchi, M.; Tokai, A.; Yoshida, T.; Water Res. 1986, $20,643$.

8. Gagnon, M. J.; Water Res. 1979, 13, 53.

9. Gagnon, M. J.; Water Res. 1983, 17, 1653.

10. Nakae, A.; Tsuji, K.; Yamanaka, M.; Anal. Chem. 1981, 53, 1818.

11. Hon-nami, H.; Hanya, T.; Water Res. 1980, 14, 1251.

12. Osburn, Q. W.; J. Am. Oil Chem. Soc. 1986, 63, 257.

13. Sandra, P.; David, F.; J. High Resolut. Chromatogr. Sci. 1990, $13,414$.

14. Yokoyama, Y.; Sato, H.; J. Chromatogr. 1991, 555, 155.

15. Nakae, A.; Tsuji, K.; Yamanaka, M.; Anal. Chem. 1980, 52, 2275.

16. Di Corcia, A.; Marchetti, M.; Samperi, R.; Anal. Chem. 1991, 63, 1179.

17. Reemtsma, T.; J. Chromatogr., A 1996, 733, 473.

18. Castles, M. A.; Moore, B. L.; Ward, S. R.; Anal. Chem. 1989, 61, 2534.

19. Mac Casthy, P.; Klusman, R. W.; Cowling, S. W.; Roce, J. A.; Anal. Chem. 1993, 65, 244R.

20. Marcomini, A.; Di Corcia, A.; Samperi, R.; Capri, S.; J. Chromatogr. 1993, 644, 59.

21. Yokoyama, Y.; Kondo, M.; Sato, H.; J. Chromatogr. 1993, 643, 169.

22. Heining, K.; Vogt, C.; Werner, G.; J. Chromatogr., A 1996, $745,281$.

23. Sáez, M.; León, V. M.; Gómez-Parra, A.; González_Mazo, E.; J. Chromatogr., A 2000, 889, 99. 
24. León, V. M.; Gómez-Parra, A.; González-Mazo, E.; Fresenius, J.; Anal. Chem. 2001, 371.

25. González -Mazo, E.; Honing, M.; Barcelo, D.; Gómez-Parra, A.; Environ. Sci. Technol. 1997, 31, 504.

26. Eichborn, P.; Flavier, M. E.; Paje, M. L.; Knepper, T. P.; Sci. Total Environ. 2001, 269, 75.

27. Riu J.; Martinez, E.; Barceló, D.; Ginebreda, A.; Fresenius, J.; Anal. Chem. 2001, 371, 448.

28. Torres P.; Ph.D. Thesis, Universidade Estadual de São Paulo, São Carlos, Brazil, 2000.

29. Miller, J. C.; Miller, J. N. Statistics for Analytical Chemistry, Ellis Horwood: Chichester, 1984.

30. Ribani, M.; Bottoli, C. B. G.; Collins, C. H.; Jardim, I. S. F.; Melo, L. F. C.; Quim. Nova 2004, 27, 771.
31. Zaiat, M.; Cabral, A. K. A.; Foresti, E.; Revista Brasileira de Engenharia - Caderno de Engenharia Química 1994, 11, 33.

32. Chen, S.; Pietrzyk, D. J.; J. Chromatogr., A 1994, 671, 73.

33. Matthijs, E.; De Henau, H.; Tenside Surfactants Deterg. 1994, 24, 193.

34. Marcomini, A.; Giger, W.; Anal. Chem. 1987, 59, 1709.

35. Linder, D. E.; Allen, M. C .; J. Am. Oil Chem. Soc. 1982, 59, 152.

36. Chen, M. H.; Horváth, C.; J. Chromatogr., A 1997, 788, 51.

Received: February 22, 2006

Published on the web: September 26, 2006

FAPESP helped in meeting the publication costs of this article. 